\title{
Humanization of Care: Key Elements Identified by Patients, Caregivers, and Healthcare Providers. A Systematic Review
}

\author{
Isolde M. Busch ${ }^{1} \cdot$ Francesca Moretti $^{2} \cdot$ Giulia Travaini $^{2} \cdot$ Albert W. Wu$^{3} \cdot$ Michela Rimondini $^{1}$ (I)
}

Published online: 15 June 2019

(c) Springer Nature Switzerland AG 2019

\begin{abstract}
Background Given the automatization of care and rationing of time and staff due to economic imperatives, often resulting in dehumanized care, the concept of 'humanization of care' has been increasingly discussed in the scientific literature. However, it is still an indistinct concept, lacking well-defined dimensions and to date no literature review has tried to capture it. Objectives The objectives of this systematic review were to identify the key elements of humanization of care by investigating stakeholders' (patients, patients' caregivers, healthcare providers) perspectives and to assess barriers and strategies for its implementation.

Methods We carried out a systematic search of five electronic databases up to December 2017 as well as examining additional sources (e.g., gray literature). Search terms included "humanization/humanisation of care" and "dehumanization/ dehumanisation of care". We conducted a thematic synthesis of the extracted study findings to identify descriptive themes and produce key elements.

Results Of 1327 records retrieved, 14 full-text articles were included in the review. Three main areas (relational, organizational, structural) and 30 key elements (e.g., relationship bonding, holistic approach, adequate working conditions) emerged. Several barriers to implementation of humanization of care exist in all areas.

Conclusion Our systematic review and synthesis contributes to a deeper understanding of the concept of humanization of care. The proposed key elements are expected to serve as preliminary guidance for healthcare institutions aiming to overcome challenges in various forms and achieve humanized and efficient care. Future studies need to fully examine specific practices of humanized care and test quantitatively their effectiveness by examining psychosocial and health outcomes.
\end{abstract}

Electronic supplementary material The online version of this article (https://doi.org/10.1007/s40271-019-00370-1) contains supplementary material, which is available to authorized users.

Michela Rimondini

michela.rimondini@univr.it

1 Section of Clinical Psychology, Department of Neuroscience, Biomedicine and Movement Sciences, University of Verona, Policlinico G.B. Rossi, Piazzale L.A. Scuro 10, 37134 Verona, Italy

2 Section of Hygiene and Preventive Medicine, Department of Diagnostic and Public Health, University of Verona, Verona, Italy

3 Department of Health Policy and Management, Johns Hopkins Bloomberg School of Public Health, Baltimore, MD, USA

\section{Key Points for Decision Makers}

Respect for patient's dignity, uniqueness, individuality, and humanity, as well as adequate working conditions and sufficient human and material resources are the most discussed key elements of humanization of care according to the different areas explored (i.e., relational, organizational, and structural, respectively).

The key elements identified are expected to help patients, caregivers, healthcare providers, and institutions in implementing humanized care.

Future studies fully examining implementation strategies of humanized care and quantitatively testing their effectiveness are warranted. 


\section{Introduction}

In recent decades, there has been a progressive increase in the use of technology in the prevention, diagnosis, treatment, and rehabilitation of disease [1]. The aim is generally to increase the quality, efficiency, and safety of care. Further, there has been an increase in specialization and subspecialization in medical settings in order to provide greater expertise in treating specific, complex diseases and conditions [2].

Although these medical developments have improved some elements of the care of patients, such as safety, effectiveness, and efficiency [3], they come with new problems. The automatization and standardization of care and the fragmentation of work and care pathways, often linked to time and staff rationing, can lead to a dehumanization and depersonalization of care [1]. There is a tendency to treat the patient as a 'group of symptoms' rather than a human with individual needs [4]. This can negatively affect the doctor-patient relationship, and undermine patients' and caregivers' trust in the healthcare system [5, 6]. Further, healthcare providers are mainly evaluated on the basis of their professional performance [7] and are often not seen as a valuable resource but as a risk in healthcare [8]. As a consequence, healthcare providers may experience stress, burnout, and compassion fatigue [7].

To overcome this counter-productive approach to healthcare, the concept of 'humanization of care' has been introduced into the scientific literature [9]. This is still a vague concept, overlapping with existing approaches to healthcare such as patient-centered care $[3,10,11]$ and person-focused care [12]. Introduced by Balint in 1969 [10], patient-centered care has been developed as an alternative to the traditional, paternalistic, disease-centered model $[10,13]$. Instead of focusing primarily on symptoms during the clinical encounter, the physician shows compassion and empathy towards the patient, respects her/his individual values, needs and preferences, and involves the patient in the decision-making process [3, 11, 14]. While patient-centered care is mainly visit- and episode-oriented [12], person-focused care adopts a more holistic perspective, considering the patient as a person with a unique personal history, and treating symptoms and diseases in the context of the course of life [12].

Humanization of care embraces these principles but also considers the other stakeholders involved in the process of care (i.e., patients, patients' caregivers, healthcare providers, policy makers) and their interactions [15-17]. This approach aims to humanize the overall healthcare system by focusing on the relational as well as organizational and structural aspects of healthcare, involving all medical tasks and procedures [16, 17] (see Fig. 1).

Patient-centered and person-focused care have been widely acknowledged in the literature, whereas the 'humanization of care' still lacks conceptual clarity and well-defined dimensions. Consequently, its implementation in clinical practice has received less study.

Todres et al. [18] introduced a theory-driven, philosophically based framework for humanizing healthcare. Following
Fig. 1 Development from patient-centered care to personfocused care to humanization of care
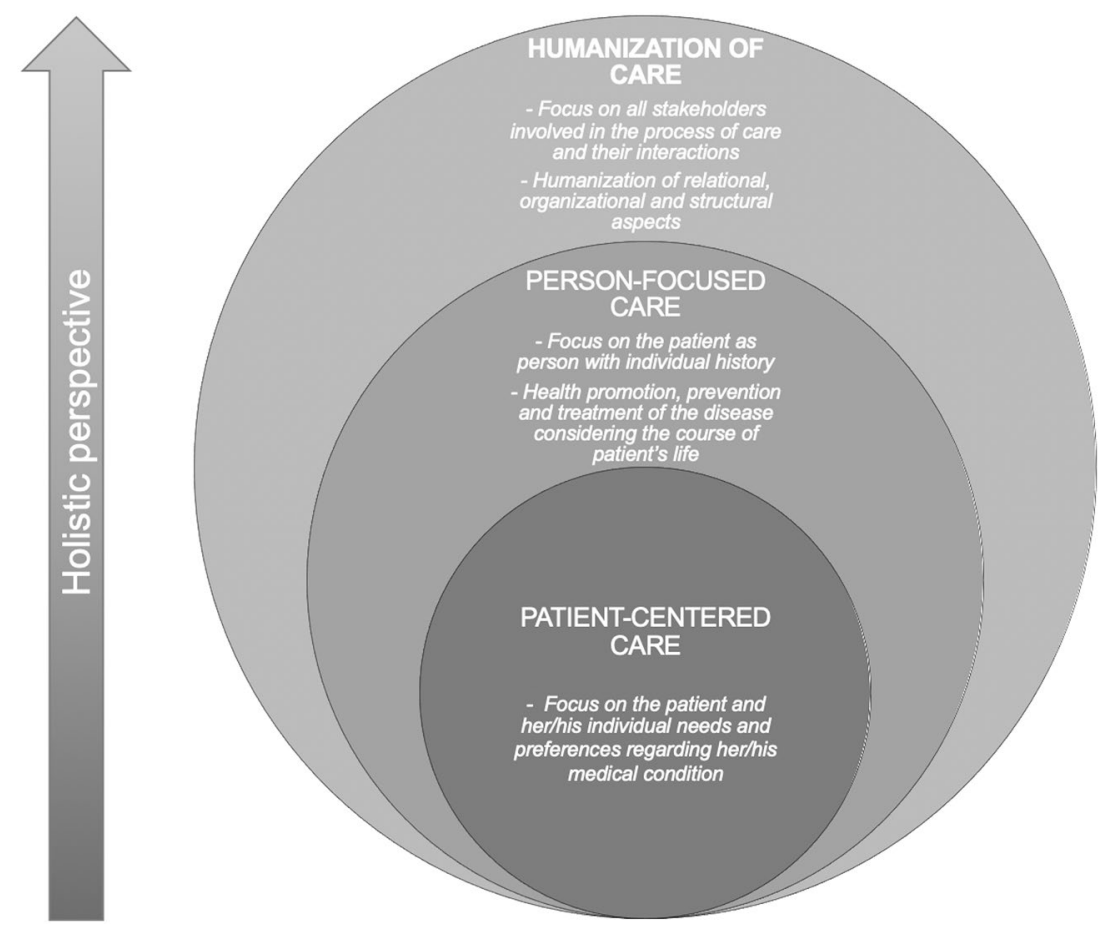
the existential-phenomenological theory, the authors define eight forms of humanization and dehumanization of care, including insiderness/objectification, agency/passivity, and uniqueness/homogenization.

Attempts to review the concept of humanization of care have been made in some clinical areas, such as in critical and pediatric care $[19,20]$. However, to date, there has not been a comprehensive review including different settings of care and capturing the voices of different stakeholders. Thus, this systematic review aimed to clarify the concept of humanization of care and identify its key elements by exploring its main features and barriers to and strategies for its implementation according to different stakeholders' (i.e., healthcare providers, patients, and patients' caregivers) perspectives.

\section{Methods}

\subsection{Search Strategy and Selection Criteria}

We conducted a systematic search of five electronic databases (Web of Science, PubMed, MEDLINE, PsycInfo, Cumulative Index of Nursing and Allied Health Literature [CINAHL]) using the search terms humanization/humanisation of care, and dehumanization/dehumanisation of care up to 31 December 2017. To detect additional studies, we searched three databases of gray literature (PsycEXTRA, OpenSIGLE database, Grey Literature Project). A detailed record of the search strategy applied in the electronic and gray literature databases is provided in Electronic Supplementary Material [ESM] Online Resource 1 and 2.

Articles were included if (i) stakeholders'/participants' (i.e., healthcare providers, patients, or patients' caregivers) understanding of the concept of humanization/dehumanization of care and/or its role in the process of care were reported and (ii) papers were published in English, Italian, or German. The following types of articles were excluded: editorials, general discussion papers, commentaries, letters, book chapters, and reviews.

The search and selection process have been recorded according to the Preferred Reporting Items for Systematic Reviews and Meta-Analyses (PRISMA) statement by Moher et al. [21]

\subsection{Data Extraction}

Two reviewers (IMB and GT) independently screened titles and abstracts of the records for inclusion using the reference management software Mendeley ${ }^{\circledR}$ (Mendeley Ltd, London, UK). The full texts of the records considered eligible by either one of the two reviewers were then independently evaluated. In cases of disagreement, the appropriateness of the inclusion/exclusion was debated, and the selection performed in consensus. If necessary, a third reviewer (FM) was involved.

Two investigators (IMB and FM) independently collected study characteristics (i.e., publication year, country, study design, setting, type of participants, sample size) and results, extracted from the 'Results', 'Findings', or 'Results \& Discussion' sections in the texts and the abstracts of the included studies, using a data collection form. In case of discrepancies, the two investigators reassessed the respective articles together.

\subsection{Quality Assessment}

Two appraisers (IMB and FM) independently assessed the quality of the included studies using the Joanna Briggs Institute Critical Appraisal Checklist for Qualitative Research [22], a standardized rating tool based on ten criteria, such as congruity between the stated philosophical perspective and the research methodology, locating the researcher culturally or theoretically, and representation of participants and their voices. The criteria can be rated as yes (i.e., met), no (i.e., unmet), unclear, and not applicable. Cases of dissent were solved through discussion.

\subsection{Data Synthesis}

We performed a thematic synthesis based on Thomas and Harden [23] with the aim of organizing and summarizing the results of the included studies. Using this method, we identified descriptive themes from which we subsequently derived key elements (see Fig. 2). Two investigators (IMB and FM) performed all steps independently. They resolved any disagreement by consensus and/or by involving a third investigator (MR).

A description of the three stages of the thematic synthesis process is given in Sects. 2.4.1 and 2.4.2.

\subsubsection{First and Second Stage: Text Coding and Developing Descriptive Themes}

We performed free line-by-line coding of the findings of the included studies, by extracting distinct text sections and coding each of them regarding their meaning and content.

Related codes were then clustered in order to develop descriptive themes. Each descriptive theme was identified as a main feature, barrier, or implementation strategy.

\subsubsection{Third Stage: Generating Key Elements}

We grouped the descriptive themes (i.e., main feature, barrier, implementation strategy) that portrayed highly similar content into newly generated key elements. We then 


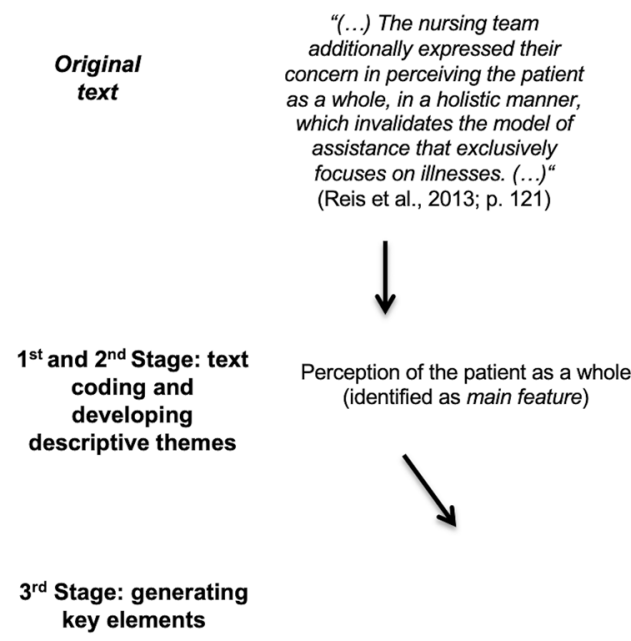

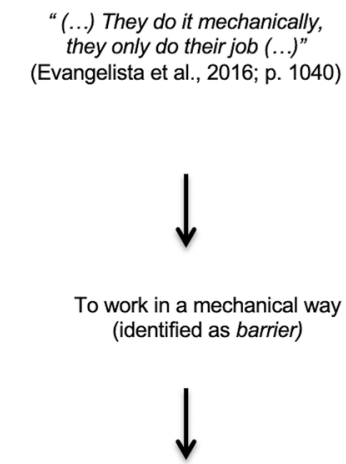

Holistic approach (assigned to the relational area)
"(...) the participants also mentioned the importance of caring, explaining that this includes receiving patients with warmth and getting to know the context in which they are inserted, and not just looking after physical aspects and their disease. (...)" (Calegari et al., 2015; p. 43)

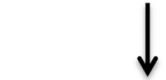

Getting to know the patient's context (identified as implementation strategy)

Fig. 2 Example of the applied thematic synthesis (based on three text sections)

assigned each key element to the relational, organizational, or structural area.

Absolute numbers and frequencies of the occurrence of key elements (i.e., overall and subdivided into healthcare providers' and patients'/patients' caregivers' perspective) across the primary studies are reported.

\section{Results}

A total of 1327 records were retrieved from the selected databases and additional sources (1324 and three, respectively). After screening for title and/or abstract, 54 full-text articles were assessed for eligibility: 34 studies were then excluded (see ESM Online Resource 3) and 20 [4, 16, 17, 24-40] included (see Fig. 3).

\subsection{Quality Assessment}

The quality of the included studies varied. All primary studies met more than half of the quality criteria, but only one study [16] met all. All studies received ethical approval by an appropriate body and demonstrated congruity between the stated philosophical perspective and the research methodology as well as between the research methodology and the research questions or objectives. The representation of the participants and their voices [26, 28], the link between the research methodology and the data collection methods [29], as well as the relationship of the conclusions to analysis or interpretation of the data [39] remained unclear for only few studies. Several articles did not clearly locate the researchers culturally or theoretically $[4,30,32,40]$ and did not draw clear connections between research methodology and data collection methods [29] and data representation and analysis [28-30, 32, 33, 35, 38, 40].

Just two studies $[4,16]$ explicitly addressed the influence of the researcher on the research, and vice versa. A detailed overview of the appraisers' judgments of each included study can be found in ESM Online Resource 4.

\subsection{Study Characteristics}

The included studies were published between 2007 and 2016 (see Table 1) and were mostly conducted in Brazil ( $n=16,80 \%$ ), as well as in four other countries (Colombia, Canada, Japan, and Australia). A qualitative design was applied in most studies ( $n=18,90 \%)$, whereas a mixedmethod approach was used only twice. Sample sizes ranged from four [17, 24] to 70 participants [29]. Thirteen studies focused on the point of view of healthcare providers (e.g., physicians, nursing professionals, midwives), four on the perspective of patients and their caregivers (e.g., family, partner), one on the patient's perspective, and two on both healthcare providers' and patients' point of view. Different medical settings (e.g., mental health, obstetrics/gynecology) were investigated.

\subsection{Thematic Synthesis}

Overall, using a thematic synthesis approach, 357 descriptive themes, defined as main features, barriers or implementation strategies, emerged. Since numerous descriptive themes were very similar to each other, we generated only 30 key elements (e.g., regarding the key element empathy towards the patient, the descriptive theme put oneself in the patient's shoes was identified seven times). 
Fig. 3 Preferred reporting items for systematic reviews and meta-analyses (PRISMA) flowchart

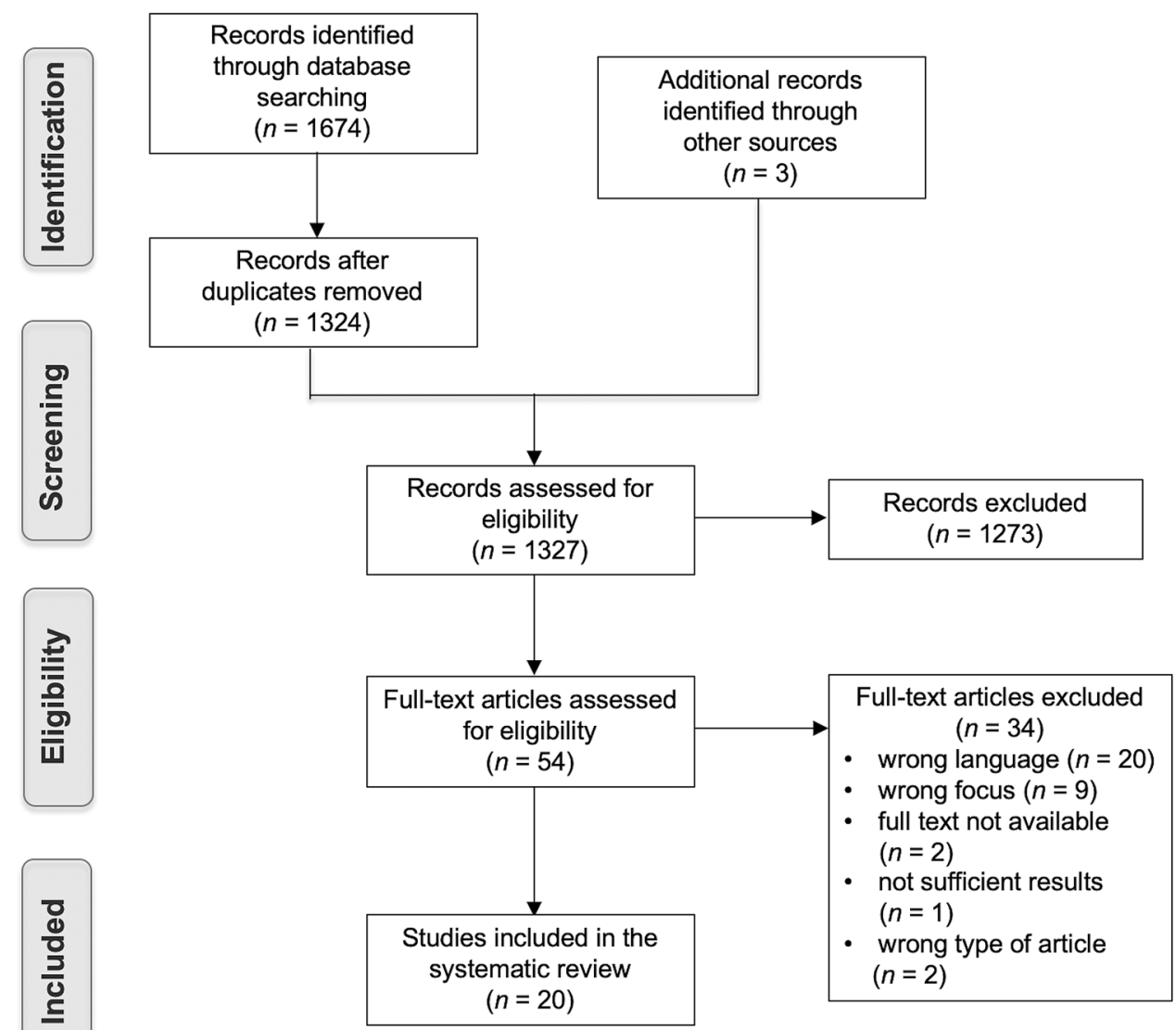

Specifically, we assigned 17 key elements to the relational (e.g., relational bonding), ten to the organizational (e.g., vertical and horizontal communication), and three to the structural area (e.g., adequate physical structure) and calculated the frequencies with which these key elements were discussed by the different stakeholders (patients, patients' caregivers, healthcare providers) (see Table 2).

Table 3 provides examples of the descriptive themes (i.e., main features, barriers, implementation strategies) representing each key element. However, for some key elements, main features, barriers, or implementation strategies did not emerge. For instance, regarding the key element psychological support for healthcare providers, participants just mentioned its lack without reporting any strategies to tackle this issue.

\subsubsection{Relational Area}

The relational area includes all key elements and related descriptive themes focusing on the aspects of humanization of care that may directly influence the personal relationship between healthcare providers and patients and their caregivers.
The following key elements were mentioned in more than half of all papers (see Table 2): respect for patient's dignity, uniqueness, individuality and humanity (90\%), empathy towards the patients (70\%), relationship bonding (65\%), holistic approach (55\%), respect for patient's autonomy and patient involvement (55\%), and verbal and non-verbal communication (50\%). Other key elements, such as healthcare provider's personal characteristics (15\%), fair-mindedness/ equity towards patients (10\%), and psychological support for healthcare providers $(10 \%)$ were mentioned only in a few studies.

Participants noted that dehumanizing behavior, such as 'othering' (i.e., treating the patient as subhuman) [27] can undermine the patient's dignity, uniqueness, individuality, and humanity. On the contrary, strategies such as referring to the patient by his/her name [36] can help the patient to feel respected and be seen as an individual.

\subsubsection{Organizational Area}

The organizational area includes all key elements and related descriptive themes linked to the work environment (e.g., workload) and the organizational and administrative practices of healthcare institutions (e.g., visiting hours). 
Table 1 Characteristics of included studies

\begin{tabular}{|c|c|c|c|c|c|c|}
\hline Study & Year & Country & Study design & Setting & Type of participants & $\begin{array}{l}\text { Sample } \\
\text { size }(n)\end{array}$ \\
\hline Backes et al. [16] & 2007 & Brazil & $\begin{array}{l}\text { Qualitative; grounded } \\
\text { theory approach }\end{array}$ & Different settings & Healthcare providers & 17 \\
\hline Baratto et al. [24] & 2016 & Brazil & $\begin{array}{l}\text { Qualitative; descriptive- } \\
\text { exploratory approach; } \\
\text { discursive textual analysis } \\
\text { technique }\end{array}$ & Oncology & Healthcare providers & 4 \\
\hline Behruzi et al. [25] & 2010 & Japan & $\begin{array}{l}\text { Qualitative field research } \\
\text { design }\end{array}$ & Obstetrics and gynecology & $\begin{array}{l}\text { Patients, healthcare provid- } \\
\text { ers }\end{array}$ & 27 \\
\hline Behruzi et al. [4] & 2014 & Canada & $\begin{array}{l}\text { Qualitative; single case } \\
\text { study design }\end{array}$ & Obstetrics and gynecology & $\begin{array}{l}\text { Patients, healthcare provid- } \\
\text { ers }\end{array}$ & 44 \\
\hline Brito and Carvalho [26] & 2010 & Brazil & $\begin{array}{l}\text { Qualitative-quantitative; } \\
\text { descriptive-exploratory } \\
\text { approach }\end{array}$ & Oncology & Patients & 10 \\
\hline Brophy et al. [27] & 2016 & Australia & $\begin{array}{l}\text { Qualitative; general induc- } \\
\text { tive approach }\end{array}$ & Mental health & $\begin{array}{l}\text { Patients, patients' caregiv- } \\
\text { ers }\end{array}$ & 66 \\
\hline Calegari et al. [28] & 2015 & Brazil & $\begin{array}{l}\text { Qualitative; descriptive- } \\
\text { exploratory approach }\end{array}$ & Different settings & Healthcare providers & 19 \\
\hline Cassiano et al. [17] & 2015 & Brazil & $\begin{array}{l}\text { Qualitative; descriptive- } \\
\text { exploratory approach; } \\
\text { thematic content analysis }\end{array}$ & Obstetrics and gynecology & Healthcare providers & 4 \\
\hline Chernicharo et al. [29] & 2014 & Brazil & $\begin{array}{l}\text { Qualitative-quantitative; } \\
\text { descriptive-explora- } \\
\text { tory approach; statisti- } \\
\text { cal method and content } \\
\text { analysis technique }\end{array}$ & Different settings & Healthcare providers & 70 \\
\hline $\begin{array}{l}\text { Coscrato and Villela Bueno } \\
\text { [30] }\end{array}$ & 2015 & Brazil & $\begin{array}{l}\text { Qualitative; descriptive- } \\
\text { exploratory approach; } \\
\text { action research method }\end{array}$ & Different settings & Healthcare providers & 49 \\
\hline Evangelista et al. [31] & 2016 & Brazil & $\begin{array}{l}\text { Qualitative; descriptive- } \\
\text { exploratory approach; } \\
\text { content analysis }\end{array}$ & Intensive care & Healthcare providers & 24 \\
\hline $\begin{array}{r}\text { Grisales-Naranjo and } \\
\text { Arias-Valencia [32] }\end{array}$ & 2013 & Colombia & $\begin{array}{l}\text { Qualitative; grounded } \\
\text { theory approach }\end{array}$ & Oncology & $\begin{array}{l}\text { Patients, patients' caregiv- } \\
\text { ers }\end{array}$ & 23 \\
\hline Marin et al. [33] & 2010 & Brazil & $\begin{array}{l}\text { Qualitative; hermeneutic- } \\
\text { dialectic approach }\end{array}$ & General practice & Healthcare providers & 20 \\
\hline Oliveira et al. [34] & 2015 & Brazil & $\begin{array}{l}\text { Qualitative; exploratory } \\
\text { approach }\end{array}$ & Mental health & Healthcare providers & 5 \\
\hline Reis et al. [35] & 2013 & Brazil & $\begin{array}{l}\text { Qualitative; descriptive- } \\
\text { exploratory approach; } \\
\text { thematic content analysis }\end{array}$ & $\begin{array}{l}\text { Neonatal and pediatric } \\
\text { intensive care }\end{array}$ & Healthcare providers & 11 \\
\hline Santos et al. [36] & 2012 & Brazil & $\begin{array}{l}\text { Qualitative; descriptive-- } \\
\text { exploratory approach; } \\
\text { collective subject } \\
\text { discourse }\end{array}$ & Anesthesia & Healthcare providers & 16 \\
\hline Silva et al. [37] & 2015 & Brazil & $\begin{array}{l}\text { Qualitative; descriptive- } \\
\text { exploratory approach; } \\
\text { thematic content analysis }\end{array}$ & Oncology & Healthcare providers & 10 \\
\hline Silva et al. [38] & 2015 & Brazil & $\begin{array}{l}\text { Qualitative; descrip- } \\
\text { tive approach; content } \\
\text { analysis }\end{array}$ & Different settings & Healthcare providers & 24 \\
\hline Spir et al. [39] & 2011 & Brazil & $\begin{array}{l}\text { Qualitative; descriptive- } \\
\text { exploratory approach; } \\
\text { content analysis }\end{array}$ & Obstetrics and gynecology & $\begin{array}{l}\text { Patients, patients' caregiv- } \\
\text { ers }\end{array}$ & 18 \\
\hline Versiani et al. [40] & 2015 & Brazil & $\begin{array}{l}\text { Qualitative; descrip- } \\
\text { tive, phenomenological } \\
\text { approach }\end{array}$ & Obstetrics and gynecology & $\begin{array}{l}\text { Patients, patients' caregiv- } \\
\text { ers }\end{array}$ & 15 \\
\hline
\end{tabular}


Table 2 Frequencies of key elements (relational, organizational, structural area) discussed by the different stakeholders

\begin{tabular}{|c|c|c|c|c|}
\hline Key element & $\begin{array}{l}\text { Studies investigating patients' } \\
\text { and patients' caregivers' } \\
\text { perspective }(n=5)[26,27, \\
32,39,40]\end{array}$ & $\begin{array}{l}\text { Studies investigating health- } \\
\text { care providers' perspective } \\
(n=13)[16,17,24,28-31 \text {, } \\
33-38]\end{array}$ & $\begin{array}{l}\text { Studies investigating health- } \\
\text { care providers' as well as } \\
\text { patients' perspective }(n=2) \\
{[4,25]}\end{array}$ & $\begin{array}{l}\text { Total number of } \\
\text { included studies } \\
(n=20)\end{array}$ \\
\hline \multicolumn{5}{|l|}{ Relational area } \\
\hline $\begin{array}{l}\text { Respect for patient's dignity, } \\
\text { uniqueness, individuality, } \\
\text { and humanity }\end{array}$ & $80 \%(4 / 5)$ & $92 \%(12 / 13)$ & $100 \%(2 / 2)$ & $90 \%(18 / 20)$ \\
\hline Empathy towards the patient & $80 \%(4 / 5)$ & $77 \%(10 / 13)$ & & $70 \%(14 / 20)$ \\
\hline Relationship bonding & $80 \%(4 / 5)$ & $69 \%(9 / 13)$ & & $65 \%(13 / 20)$ \\
\hline Holistic approach & $20 \%(1 / 5)$ & $69 \%(9 / 13)$ & $50 \%(1 / 2)$ & $55 \%(11 / 20)$ \\
\hline $\begin{array}{l}\text { Respect for patient's } \\
\text { autonomy and patient } \\
\text { involvement }\end{array}$ & $60 \%(3 / 5)$ & $46 \%(6 / 13)$ & $100 \%(2 / 2)$ & $55 \%(11 / 20)$ \\
\hline $\begin{array}{l}\text { Verbal and non-verbal com- } \\
\text { munication }\end{array}$ & $60 \%(3 / 5)$ & $46 \%(6 / 13)$ & $50 \%(1 / 2)$ & $50 \%(10 / 20)$ \\
\hline $\begin{array}{l}\text { Meeting patient's needs/ } \\
\text { demands }\end{array}$ & $60 \%(3 / 5)$ & $39 \%(5 / 13)$ & $50 \%(1 / 2)$ & $45 \%(9 / 20)$ \\
\hline Commitment & $60 \%(3 / 5)$ & $23 \%(3 / 13)$ & & $30 \%(6 / 20)$ \\
\hline Moral and ethical principles & $20 \%(1 / 5)$ & $39 \%(5 / 13)$ & & $30 \%(6 / 20)$ \\
\hline $\begin{array}{l}\text { Relational support for the } \\
\text { patient and patient's car- } \\
\text { egivers }\end{array}$ & $40 \%(2 / 5)$ & $23 \%(3 / 13)$ & $50 \%(1 / 2)$ & $30 \%(6 / 20)$ \\
\hline $\begin{array}{l}\text { Being attentive/interested/ } \\
\text { concerned towards the } \\
\text { patient }\end{array}$ & $40 \%(2 / 5)$ & $23 \%(3 / 13)$ & & $25 \%(5 / 20)$ \\
\hline $\begin{array}{l}\text { Healthcare provider's com- } \\
\text { petence }\end{array}$ & $80 \%(4 / 5)$ & $8 \%(1 / 13)$ & & $25 \%(5 / 20)$ \\
\hline Patience & $60 \%(3 / 5)$ & $15 \%(2 / 13)$ & & $25 \%(5 / 20)$ \\
\hline $\begin{array}{l}\text { Transparency regarding the } \\
\text { treatment }\end{array}$ & $40 \%(2 / 5)$ & $15 \%(2 / 13)$ & & $20 \%(4 / 20)$ \\
\hline Fair-mindedness/equity & $20 \%(1 / 5)$ & $8 \%(1 / 13)$ & & $10 \%(2 / 20)$ \\
\hline $\begin{array}{l}\text { Healthcare provider's per- } \\
\text { sonal characteristics }\end{array}$ & $40 \%(2 / 5)$ & $8 \%(1 / 13)$ & & $15 \%(20)$ \\
\hline $\begin{array}{l}\text { Psychological support for } \\
\text { healthcare providers }\end{array}$ & & $8 \%(1 / 13)$ & $50 \%(1 / 2)$ & $10 \%(2 / 20)$ \\
\hline \multicolumn{5}{|l|}{ Organizational area } \\
\hline Adequate working conditions & $20 \%(1 / 5)$ & $62 \%(8 / 13)$ & $50 \%(1 / 2)$ & $50 \%(10 / 20)$ \\
\hline Adequate training & $20 \%(1 / 5)$ & $46 \%(6 / 13)$ & $50 \%(1 / 2)$ & $40 \%(8 / 20)$ \\
\hline Team work & $40 \%(2 / 5)$ & $39 \%(5 / 13)$ & $50 \%(1 / 2)$ & $40 \%(8 / 20)$ \\
\hline Continuity of care & $20 \%(1 / 5)$ & $23 \%(3 / 13)$ & $100 \%(2 / 2)$ & $30 \%(6 / 20)$ \\
\hline $\begin{array}{l}\text { Appropriate medical treat- } \\
\text { ment }\end{array}$ & $60 \%(3 / 5)$ & $8 \%(1 / 13)$ & $50 \%(1 / 2)$ & $25 \%(5 / 20)$ \\
\hline $\begin{array}{l}\text { Organizational support for } \\
\text { the patient and patient's } \\
\text { caregivers }\end{array}$ & $20 \%(1 / 5)$ & $15 \%(2 / 13)$ & $100 \%(2 / 2)$ & $25 \%(5 / 20)$ \\
\hline $\begin{array}{l}\text { Facilitated access to health- } \\
\text { care }\end{array}$ & $60 \%(3 / 5)$ & $8 \%(1 / 13)$ & & $20 \%(4 / 20)$ \\
\hline $\begin{array}{l}\text { Vertical and horizontal com- } \\
\text { munication }\end{array}$ & & $23 \%(3 / 13)$ & & $15 \%(3 / 20)$ \\
\hline Pleasant hospital stay & $40 \%(2 / 5)$ & $8 \%(1 / 13)$ & & $15 \%(3 / 20)$ \\
\hline Adequate priority assessment & & $8 \%(1 / 13)$ & $50 \%(1 / 2)$ & $10 \%(2 / 20)$ \\
\hline \multicolumn{5}{|l|}{ Structural area } \\
\hline Human and material resources & $20 \%(1 / 5)$ & $54 \%(7 / 13)$ & $50 \%(1 / 2)$ & $45 \%(9 / 20)$ \\
\hline Adequate physical structure & $40 \%(2 / 5)$ & $31 \%(4 / 13)$ & $50 \%(1 / 2)$ & $35 \%(7 / 20)$ \\
\hline
\end{tabular}


Table 2 (continued)

\begin{tabular}{llll}
\hline Key element & $\begin{array}{l}\text { Studies investigating patients' } \\
\text { and patients' caregivers' } \\
\text { perspective }(n=5)[26,27, \\
32,39,40]\end{array}$ & $\begin{array}{l}\text { Studies investigating health- } \\
\text { care providers' perspective } \\
(n=13)[16,17,24,28-31,\end{array}$ & $\begin{array}{l}\text { Studies investigating health- } \\
\text { care providers' as well as } \\
\text { patients' perspective }(n=2) \\
{[4,25]}\end{array}$ \\
\hline Pleasant environment & $\begin{array}{l}\text { Total number of } \\
\text { included studies } \\
(n=20)\end{array}$ \\
\hline
\end{tabular}

While the key elements adequate working conditions, adequate training, and team work were mentioned in more than one-third of all papers $(50 \%, 40 \%$, and $40 \%$, respectively), other key elements, such as vertical and horizontal communication, pleasant hospital stay, and adequate priority assessment were covered much less often (15\%, 15\%, and $10 \%$, respectively) (see Table 2 ).

While the fragmentation of the work process [31] was seen as a barrier, the efficient use of time [29] was considered as a strategy to improve the working conditions.

\subsubsection{Structural Area}

The structural area encompasses all key elements and the associated descriptive themes that focus on the structure of healthcare institutions (e.g., hospital design) and the work environment (e.g., material resources) regarding humanization of care.

Two of the three key elements in this area were mentioned in more than one-third of the included studies: human and material resources (45\%) and adequate physical structure $(35 \%)$. The third key element (pleasant hospital stay) was mentioned only twice (10\%) (see Table 2).

It has been often reported (e.g., Cassiano et al. [17], Chernicharo et al. [29]) that sufficient human and material resources are required for providing humanized care. Nevertheless, in many healthcare institutions there was a lack of material resources [29] and health professionals [24, 31, $33,34]$. Including volunteers in the routine hospital practice [26] was considered a strategy to overcome this obstacle.

\subsubsection{Stakeholders' Perspectives}

Comparing the studies focusing either on the patients' and patients' caregivers' perspective $(n=5)$ or on healthcare providers' perspective $(n=13)$ alone, it emerged that when patients and patients' caregivers were assessed, the key elements psychological support for healthcare providers (relational area), vertical and horizontal communication, adequate priority assessment (organizational area), and pleasant environment (structural area) were not discussed. Some other key elements, such as holistic approach $(20 \%$ vs. $69 \%$ ), adequate working conditions (20\% vs. $62 \%$ ), and human and material resources (20\% vs. $54 \%$ ) were mentioned notably less often, and some were mentioned more, such as commitment (60\% vs. $23 \%$ ), patience (60\% vs. $15 \%)$, healthcare provider's competence ( $80 \%$ vs. $8 \%$ ), healthcare provider's personal characteristics (40\% vs. $8 \%$ ), appropriate medical treatment (60\% vs. $8 \%$ ), facilitated access to healthcare (60\% vs. $8 \%$ ), and pleasant hospital stay (40\% vs. $8 \%$ ) (see Table 2). However, some key elements were discussed by patients and patients' caregivers as well as by healthcare providers to a similarly small (e.g., fairmindedness/equity, organizational support for the patient and patient's caregivers) or great extent (e.g., respect for patients' dignity, uniqueness, individuality, and humanity, empathy towards the patient, relationship bonding).

Further, regarding the two studies investigating both patients and healthcare providers, it was found that several key elements of the relational, organizational, as well as structural area (e.g., empathy towards the patient, relationship bonding, facilitated access to healthcare, pleasant environment) were not mentioned at all.

\section{Discussion}

To our knowledge, this is the first systematic review examining the concept of humanization of care from the perspective of the involved stakeholders and aiming to create a shared understanding about what delivering humanized care means and how it can be implemented. Our analysis revealed that gaps between the expectations of all the protagonists involved in the process of care and routine clinical practice still exist.

\subsection{Relational Area}

The relational area turned out to be the one most explored and discussed, which demonstrates the importance of relationships in humanized care.

The key elements relationship bonding, discussed in two-thirds of the included studies, and relational support for the patient and patient's caregivers reflect the need for a genuine relationship between healthcare providers, patients, and caregivers. This highlights that it is not sufficient to simply treat the disease or the symptoms. As mentioned by the participants, being attentive/interested/concerned towards the patient and sensitive verbal/non-verbal communication are important means for establishing such a connection, as 


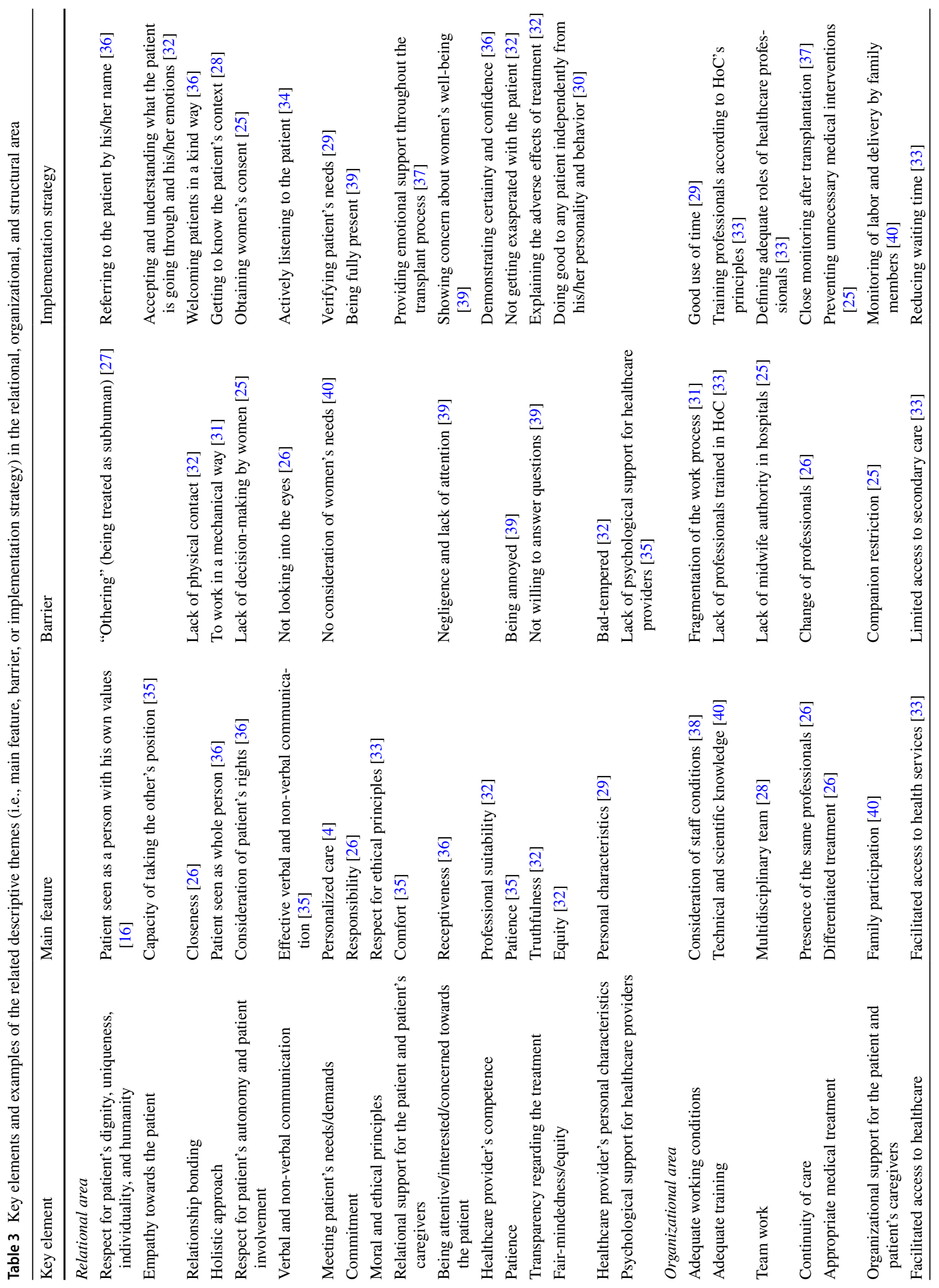


previously demonstrated [41-43]. According to the National Patient Safety Foundation's (NPSF) Lucian Leape Institute, "the experience of trust and partnership is itself valuable, satisfying, and fulfilling to patients, families, clinicians, and staff alike" (p. 6) [44].

Besides relationship bonding, empathy towards the patient and respect for patient's dignity, uniqueness, individuality, and humanity were also highly discussed by the large majority of stakeholders in the included studies $(70 \%$ and $90 \%$, respectively) as elements of humanization of care. In agreement with such evidence, several authors have already linked empathy to an improved therapeutic relationship [45] and to higher patient satisfaction [45-47]. According to our results, the key element respect for patient's dignity, uniqueness, individuality, and humanity points to the understanding that every patient is a unique person with their own values, expectations, and life experiences that have shaped the patient's identity and relational style and which might have been shattered by the disease. A severe disease might also reduce the patient's perceptions of dignity due to a loss of functionality and reduced control over their body and daily activities $[48,49]$. Healthcare providers can promote patients' dignity by developing a deep understanding of how conditions of the disease affect the patient's life, emphatically acknowledging patient's suffering, and, at the same time, trying to emphasize the characteristics less affected by the disease. A study by Beach et al. [50] showed that being treated with dignity is linked to higher patient satisfaction and therapy adherence.

Closely related is the key element holistic approach, which was mainly mentioned by healthcare providers who might have been more familiar with this medical concept than patients and their caregivers. The concept refers to the need to take into account all the biopsychosocial and spiritual dimensions of the patient, disease, and care, and to see the patient as a biopsychosocial being. Such an approach recognizes that the mind has a strong impact on the body and that we need to ensure a form of care that addresses both body and mind in order to be effective [51]. As early as 1996, the World Health Organization (WHO) Study Group saw integrated care, in which all the components of a health system play a complementary role to ensure patients' wellbeing, as a way to approach health holistically and to foster personalized services [52, 53].

Further, showing respect for patient's autonomy and patient involvement and meeting patient's needs/demands were mentioned in half of the included studies $(55 \%$ and $45 \%$, respectively) as a means for humanizing healthcare. Thus, as an example, excluding women from decision-making processes in their own care [25] or ignoring women's needs [40] can represent barriers to the humanization of care. Overwhelming evidence indicates that engaging patients in their own care and thus taking patients' preferences and 
needs seriously improves patient satisfaction, empowerment, quality of life, and treatment outcomes [54-56]. Transparency regarding the treatment was considered, more so by patients and their caregivers than by healthcare providers, to be another key element. Consequently, not being willing to answer patients' questions [39] can impede humanized care. A complete understanding of one's own medical condition and treatment options gives the patient the feeling of autonomy, of being respected, and of being seen as an equal partner. As highlighted by the NPSF's Lucian Leape Institute [57], greater transparency is linked to higher patient satisfaction, better health outcomes, lower costs, and also fewer medical errors.

Healthcare provider's personal characteristics and healthcare provider's competence were rarely mentioned in studies exploring the healthcare providers' perspective, probably because they did not question themselves. On the contrary, almost all studies analyzing the patients' viewpoint reported competence as an aspect of humanized care. Psychological preparation to understand the patient was reported as one strategy to convey such competence. Thus, professional competence should be understood not only in terms of technical but also non-technical skills. Equipping healthcare providers with such psychosocial abilities should become an integral aim of medical education.

Moreover, according to our findings, healthcare providers should follow moral and ethical principles, be fair-minded and treat all patients equally (fair-mindedness/equity), and show patience and commitment to their jobs. However, being committed, patient, and empathic towards patients is challenging when experiencing distress or even burnout $[58,59]$ due to seemingly overwhelming work demands and time constraints. Healthcare providers may then rush through patient encounters while experiencing a loss of enthusiasm, dedication, and meaning [60]. Given these circumstances, it is surprising that only two studies [25, 35] pointed out that healthcare organizations do not provide sufficient psychological support for healthcare providers. Healthcare staff will only be able to truly care for patients and deliver humanized care if their own human needs are also addressed.

\subsection{Organizational Area}

Adequate working conditions was the most discussed key element in the organizational area. According especially to the opinion of healthcare providers, fragmentation of the work process, lack of time, intense routine at work, excessive demands on healthcare providers, excessive bureaucratic activities, and additional activities out of professionals' scope impose significant barriers to achieving humanized care. When organizations are able to overcome these barriers, establish proper working conditions, and thus demonstrate that healthcare providers' well-being is of great importance, healthcare providers will experience higher levels of job satisfaction, be less susceptible to burnout, and provide better care [61].

Although less frequently reported, adequate training opportunities for healthcare providers, effective interdisciplinary team work as well as proper vertical and horizontal communication in the institution were listed, especially by healthcare providers, as organizational requirements for providing humanized care. However, as pointed out by the participants of the included studies, several barriers to these key elements continue to exist in healthcare institutions, such as a still widespread traditional approach to medical education and training [33], a strict hospital hierarchy [25], and lack of cooperation from the management [17].

In contrast, regarding patient care itself, mostly patients and their caregivers called for appropriate medical treatment tailored to patients' needs and facilitated access to healthcare to ensure humanized care. Open and easy access to primary care has also been demonstrated to play a significant role in reducing, for instance, healthcare inequalities, mortality, morbidity, and costs [62]. Healthcare organizations should also guarantee continuity of care by avoiding, for example, frequent changes of healthcare professionals [26] and provide organizational support for the patients and their caregivers. Further, a pleasant hospital stay, without, for instance, interruptions to sleep [26] or long intervals between lunch and dinner [39], was valued by patients and their caregivers, as already shown in the literature [63]. Two studies also highlighted the importance of adequate priority assessment of medical care (i.e., to find a compromise between ensuring effective care and life-saving treatment, such as in intensive care situations [4], and delivering humanized care), as also discussed by Todres et al. [18, 64].

\subsection{Structural Area}

Due to economic imperatives and increased demands (e.g., the aging population, an increase in chronic diseases), healthcare systems have been struggling lately with a critical shortage of healthcare personnel and lack of material resources [65-67], which were considered in the included studies as barriers to humanized care. According to the American Association of Colleges of Nursing, insufficient staffing leads to increased stress levels among nurses, reduced job satisfaction, and dropouts [61]. Meaningful personal relationships with patients have become challenging tasks carried out under immense time pressure [61]. Thus, to give healthcare providers the chance to spend time directly engaging with patients and caring for them, healthcare institutions must provide sufficient human and material resources.

Healthcare settings, not lacking in space [35] and with an adequate physical structure and pleasant environment were 
also considered to be structural aspects of humanized care. Indeed, factors such as floor and room layouts and lighting have been shown to positively influence health outcomes [68-70].

\subsection{Limitations}

A number of limitations may have influenced our results. All primary studies applied qualitative or quantitative-qualitative methods and had small sample sizes, thus limiting data rigidity and replicability, and reducing the generalizability of the findings. However, by using qualitative approaches, such as focus groups and interviews, each of the included studies was able to provide an insight into healthcare practices and the 'lived experience' of patients and healthcare providers in the field of humanization of care [71, 72].

Intrinsic limitations associated with the applied methodology of our study have to be considered as well. First, despite extensively searching published and gray literature in the medical field, we may have nevertheless missed relevant studies in the field of humanities which could have impacted our results. It is also likely that our applied search terms "humanization/humanisation of care" and "dehumanization/dehumanisation of care" did not capture studies that investigated elements of humanized care (e.g., liberal visitation policies in pediatric care) but did not specifically use the terms "humanization" and "dehumanization". Further, because of our restriction to include only studies published in English, German, or Italian, we may have missed otherwise eligible studies that could have contributed to a broader geographical and cultural scope of the findings.

Moreover, the methodological steps of the thematic analysis can be prone to subjectivity. To limit this potential bias, two reviewers performed all steps independently and resolved any disagreement in consensus and/or by involving a third reviewer. One might argue that summarizing and synthesizing the results of the primary studies, conducted in different medical settings with participants from various backgrounds, could lead to a decontextualization of the findings [23]. Following Thomas and Harden [23], we therefore tried to preserve context by providing detailed characteristics (e.g., study design, setting, type of participants) and quality assessment for each study. Further, we consistently examined whether the results that emerged from our synthesis could be translated into other medical settings without loss of meaning [23].

Lastly, the generalizability of our findings is hampered by the fact that most of the research was conducted in Brazil. This geographical predominance is not surprising given the fact that since the introduction of the Brazilian National Policy of Humanization of Care and Management in 2003, Brazil has devoted great effort to establishing humanized care, specifically in medical settings that deal with very fragile patients (e.g., newborn/infants or oncological patients) or where risk of dehumanization is high (e.g., extensive use of technology in intensive care) $[73,74]$.

\subsection{Future Studies}

Although we were able to extract numerous key elements of humanization and point out similarities and differences between patients' and professionals' perspectives, we identified only a few implementation strategies, which were often insufficient to add actionable information. Thus, further research around humanization of care is warranted.

Future studies need to fully examine specific practices of humanized care and test their effectiveness quantitatively by examining psychosocial and health outcomes. Moreover, to examine how the concept of humanization of care might be shaped by the culture we live in, research on humanization of care should be increased in many countries, thus providing a global perspective. To ensure that future literature reviews on humanization of care are able to capture all potentially eligible studies from around the world and thus to provide an even clearer picture of the key elements of humanized care, the search criteria of this study might be expanded. Indeed, the literature search could be extended to other scientific areas, language restrictions might be omitted, and the search strategy could include more terms. The key elements identified by our study may even serve as additional search terms. Future research aiming to identify an even more articulated structure composed of additional sub-constructs within the relational, organizational, and structural area could be beneficial for formalizing a model of humanization of care and for assessing model-consistent interventions to improve outcomes.

\section{Conclusions}

By synthesizing and thematically analyzing the different perspectives of patients, caregivers, and healthcare providers, our systematic review contributes to a better understanding of the concept of humanization of care. An empathetic and respectful approach to patients, sufficient human and material resources in healthcare institutions, and a balanced workload for healthcare providers are important prerequisites for establishing meaningful, mutually beneficial relationships with patients and delivering humanized care. The key elements proposed here can be considered as preliminary guidance that can help patients, caregivers, healthcare providers, and healthcare institutions in this endeavor. 


\section{Compliance with Ethical Standards}

Conflict of Interest Isolde M. Busch, Francesca Moretti, Giulia Travaini, Albert W. Wu, and Michela Rimondini declare that they have no conflict of interest directly related to the content of this systematic review.

Funding The authors received no specific funding for this work.

Informed Consent For this type of study, formal consent is not required.

Ethics Approval For this type of study, ethics approval is not required.

Data Availability Statement The full datasets of the systematic review can be made available upon reasonable request.

\section{References}

\section{*Studies included in the systematic review}

1. Lovato E, Minniti D, Giacometti M, Sacco R, Piolatto A, Barberis $B$, et al. Humanisation in the emergency department of an Italian hospital: new features and patient satisfaction. Emerg Med J. 2013;30:487-91.

2. Langdon LO, Toskes PP, Kimball HRM. The American Board of Internal Medicine Task Force on subspecialty internal medicine. Future roles and training of internal medicine subspecialists. Ann Intern Med. 1996;124:686-91.

3. Institute of Medicine (US) Committee on Quality of Health Care in America. Crossing the quality chasm: a new health system for the 21 st century. National Academies Press (US), Washington, DC (2001).

*4. Behruzi R, Hatem M, Goulet L, Fraser WD. Perception of humanization of birth in a highly specialized hospital: let's think differently. Health Care Women Int. 2014;35:127-48.

5. Kienzle HF. Fragmentation of the doctor-patient relationship as a result of standardization and economization [in German]. Z Arztl Fortbild Qualitatssich. 2004;98(3):193-9 (discussion 206, 2013-5).

6. Stange KC. The problem of fragmentation and the need for integrative solutions. Ann Fam Med. 2009;7:100-3.

7. Rosenstein AH. Addressing physician stress, burnout, and compassion fatigue: the time has come. Isr J Health Policy Res. 2013;2:32.

8. Hollnagel E, Wears RL, Braithwaite J. From safety-I to safety-II: a white paper. The Resilient Health Care Net: Published simultaneously by the University of Southern Denmark, University of Florida, USA, and Macquarie University, Australia; 2015.

9. Borbasi S, Galvin KT, Adams T, Todres L, Farrelly B. Demonstration of the usefulness of a theoretical framework for humanising care with reference to a residential aged care service in Australia. J Clin Nurs. 2012;22:881-9.

10. Balint E. The possibilities of patient-centred medicine. J R Coll Gen Pract. 1969;17:269-76.

11. Gerteis M, Edgman-Levitan S, Daley J. Through the patient's eyes. Under-standing and promoting patient-centered care. San Francisco: Jossey-Bass; 1993.

12. Starfield B. Is patient-centered care the same as person-focused care? Perm J. 2011;15:63-9.
13. Drolet BC, White CL. Selective paternalism. Virtual Mentor. 2012;14:582-8.

14. Barry MJ, Edgman-Levitan S. Shared decision making-pinnacle of patient-centered care. N Engl J Med. 2012;366:780-1.

15. Umenai T, Wagner M, Page LA, Page LA, Faundes A, Rattner $\mathrm{D}$, et al. Conference agreement on the definition of humanization and humanized care. Int J Gynecol Obstet. 2001;75:S3-4.

*16. Backes DS, Koerich MS, Erdmann AL. Humanizing care through the valuation of the human being: resignification of values and principles by health professionals. Rev Latino-am Enfermagem. 2007;15:34-41.

*17. Cassiano AN, Araujo MG, Holanda CSM, Costa RKS. Perception of nurses on humanization in nursing care in immediate puerperium. J Res Fundam Care. 2015;7:2051-60.

18. Todres L, Galvin KT, Holloway I. The humanization of healthcare: a value framework for qualitative research. Int J Qual Stud Health Well-being. 2009;4:68-77.

19. Garcia-Salido A, Heras la Calle G, Serrano Gonzalez A. Narrative review of pediatric critical care humanization: where we are? Med Intensive. 2019;43(5):290-8. https://doi. org/10.1016/j.medin.2018.01.006.

20. Galvin I, Leitch J, Gill R, Poser K, McKoewn S. Humanization of critical care-psychological effects on healthcare professional and relatives: a systematic review. Can J Anesth. 2018;65(12):1348-71. https://doi.org/10.1007/s1263 0-018-1227-7.

21. Moher D, Liberati A, Tetzlaff J, Altman DG. Preferred reporting items for systematic review and meta-analyses: the PRISMA statement. PLoS Med. 2009;6:e1000097.

22. Joanna Briggs Institute. The Joanna Briggs Institute Critical Appraisal tools for use in JBI Systematic Reviews. Checklist for Qualitative Research. 2017. https://joannabriggs.org/criti cal_appraisal_tools. Accessed 17 Mar 2019.

23. Thomas J, Harden A. Methods for the thematic synthesis of qualitative research in systematic reviews. BMC Med Res Methodol. 2008;8:45.

*24. Baratto F, Ferreira CLL, Ilha S, Santos Nunes S, Backes DS, Asta Pereiitora A. Humanization of care in primary care to people with neoplasia: perception of nursing professionals. J Nurs UFPE on line. 2016;10:615-22.

*25. Behruzi R, Hatem M, Fraser W, Goulet L, Ii M, Misago C. Facilitators and barriers in the humanization of childbirth practice in Japan. BMC Pregnancy Childbirth. 2010;10:25.

*26. Brito NTG, Carvalho R. Humanization according to cancer patients with extended hospitalization periods. Einstein. 2010;8:221-7.

*27. Brophy LM, Roper CE, Hamilton BE, Tellez JJ, McSherry BM. Consumers and carer perspectives on poor practice and the use of seclusion and restraint in mental health settings: results from Australian focus groups. Int Ment Health Syst. 2016;10:6.

*28. Calegari Rde C, Massarollo MC, Santos MJ. Humanization of health care in the perception of nurses and physicians of a private hospital. Rev Esc Enferm USP. 2015;49:42-7.

*29. Chernicharo IM, Silva FD, Ferreira MA. Description of the term humanization in care. Esc Anna Nery. 2014;18:156-62.

*30. Coscrato G, Villela Bueno SM. Spirituality and humanization according to nursing undergraduates: an action research. Invest Educ Enferm. 2015;33:73-82.

*31. Evangelista VC, Domingos TD, Siqueira FP, Braga EM. Multidisciplinary team of intensive therapy: humanization and fragmentation of the work process. Rev Bras Enferm. 2016;69:1099-107.

*32. Grisales-Naranjo LV, Arias-Valencia MM. Humanized care; the case of patients subjected to chemotherapy. Invest Educ Enferm. 2013;31:364-76.

*33. Marin MJS, Storniolo LV, Moravcik MY. Humanization of care from the perspective of the family health strategy teams in a city 
in the interior of São Paulo. Brazil. Rev Latino-Am Enfermagem. 2010;18:763-9.

*34. Oliveira LC, Silva RAR, Medeiros MN, Queiroz JC, Giumarães J. Humanized care: discovering the possibilities in the practice of nursing in mental health. J Res Fundam Care. 2015;7:1774-82.

*35. Reis LS, Silva EF, Waterkemper R, Lorenzini E, Cecchetto FH. Humanization of healthcare: perception of a nursing team in a neonatal and paediatric intensive care unit. Rev Gaúche Enferm. 2013;34:118-24.

*36. Santos MFO, Fernandes MGM, Oliveira HJ. Receptiveness and humanization from the perceptive of anesthesiologists. Rev Bras Anestesiol. 2012;62:199-213.

*37. Silva RM, Santos KB, Silva GA, Reis VN, Andrade AM. Humanization of care in bone marrow transplantation: the perception of the nursing team. J Nurs UFPE on line. 2015;9:8261-9.

*38. Silva RM, Oliveira DC, Pereira ER. The discursive production of professionals about humanizing health: singularity rights and ethics. Rev Latino-Am Enfermagem. 2015;23:936-44.

*39. Spir EG, Soares AVN, Wei CY, Aragaki IM, Kurcgant P. The accompanying mothers' perception about humanization of assistance at a neonatal unit. Rev Esc Enferm USP. 2011;45:1048-54.

*40. Versiani CC, Barbieri M, Gabrielloni MC, Fustinoni SM. The meaning of humanized childbirth for pregnant women. J Res Fundam Care Online. 2015;7:1927-35.

41. Henry SG, Fuhrel-Forbis A, Rogers MA, Eggly S. Association between nonverbal communication during clinical interactions and outcomes: a systematic review and meta-analysis. Patient Educ Couns. 2012;86:297-315

42. Ha JF, Longnecker N. Doctor-patient communication: a review. Ochsner J. 2010;10:38-43.

43. Frampton SB, Guastello S. Time to embrace a new patient-centered care rallying cry: "why not?". Patient. 2014;7:231-3.

44. National Patient Safety Foundation's Lucian Leape Institute. Safety is personal: partnering with patients and families for the safest care. Boston: National Patient Safety Foundation; 2014.

45. Haslam N. Humanising medical practice: the role of empathy. Med J Aust. 2007;187:381-2.

46. Uhas Adam A, Chamacho FT, Feldman SR, Balkrishnan R. The relationship between physician friendliness and caring, and patient satisfaction. Findings from an internet-based service. Patient. 2008;1:91-6.

47. Elliott R, Bohart AC, Watson JC, Greenberg LS. Empathy. In: Norcross J, editor. Psychotherapy relationships that work. New York: Oxford University Press; 2011. p. 132-52.

48. Rodriguez-Prat A, Monforte-Rozo C, Porta-Sales J, Escribano X, Balaguer A. Patient perspectives of dignity, autonomy and control at the end of life: Systematic review and meta-ethnography. PLoS One. 2016;11:e0151435.

49. Pringle J, Johnston B, Buchanan D. Dignity and patient-centred care for people with palliative care needs in the acute hospital setting: a systematic review. Palliat Med. 2015;29:675-94.

50. Beach MC, Sugarman J, Johnson RL, Arbelaez JJ, Duggan PS, Cooper LA. Do patients treated with dignity report higher satisfaction, adherence, and receipt of preventive care? Ann Fam Med. 2005;3:331-8.

51. Davis-Floyd R. The technocratic, humanistic, and holistic paradigms of childbirth. Int J Gynecol Obstet. 2001;75:S5-23.

52. WHO Study Group on Integration of Health Care Delivery Health Organization (1994: Geneva, Switzerland) and World Health Organization (1996). Integration of health care delivery: report of a WHO study group. Geneva: World Health Organization. http://www.who. int/iris/handle/10665/38408. Accessed 17 Mar 2019.

53. Kodner DL, Spreeuwenberg C. Integrated care: meaning, logic, applications, and implications - a discussion paper. Int J Integr Care. 2002;2:e12.
54. Ashraf AA, Colakoglu S, Nguyen JT, Anastasopulos AJ, Ibrahim $\mathrm{AM}$, Yueh JH, et al. Patient involvement in the decision-making process improvement satisfaction and quality of life in postmastectomy breast reconstruction. J Surg Res. 2013;184:665-70.

55. Tambuyzer E, Van Audenhove C. Is perceived patient involvement in mental health care associated with satisfaction and empowerment? Health Expect. 2015;18:516-26.

56. Vahdat S, Hamzehgardeshi L, Hessam S, Hamzehgardeshi Z. Patient involvement in health care decision making: a review. Iran Red Cres Med J. 2014;16:e12454.

57. The National Patient Safety Foundation's Lucian Leape Institute. Shining a light. Safer health care through transparency. Boston: National Patient Safety Foundation; 2015.

58. Maslach C, Schaufeli WB, Leiter MP. Job burnout. Ann Rev Psychol. 2001;52:397-422.

59. Bianchi R, Schonfeld IS, Laurent E. Is it time to consider the "burnout syndrome" a distinct illness? Front Public Health. 2015;3:158.

60. Gandhi TK, Kaplan GS, Leape L, Berwick DM, Edgman-Levitan S, Edmondson A, et al. Transforming concepts in patient safety: a progress report. BMJ Qual Saf. 2018;27:1019-26.

61. National Patient Safety Foundation's Lucian Leape Institute. Through the eyes of the workforce. Creating joy, meaning, and safer health care. National Patient Safety Foundation, Boston; 2013.

62. Peart A, Lewis V, Brown T, Russell G. Patient navigators facilitating access to primary care: a scoping review. BMJ Open. 2018;8:e019252.

63. Patterson ES, Sanders EBN, Sommerich CM, Lavender SA, Li J, Evans KD. Meeting patient expectations during hospitalization: a grounded theoretical analysis of patient-centered room elements. HERD. 2017;10:95-110.

64. Todres L, Fulbrok P, Albarran J. On the receiving end: a hermeneutic-phenomenological analysis of a patient's struggle to cope while going through intensive care. Nurs Crit Care. 2000;5:277-87.

65. Association of American Medical Colleges. The complexities of physician supply and demand: projections from 2016 to 2030. 2018 update. Final report. 2018. https://www.heartland.org/publicationsresources/publications/the-complexities-of-physician-supply-anddemand-projections-from-2016-to-2030. Accessed 17 Mar 2019.

66. Rowe JW, Fulmer T, Fried L. Preparing for better health and health care for an aging population. JAMA. 2016;316:1643-4.

67. Henderson J, Willis E, Toffoli L, Hamilton P, Blackman I. The impact of rationing of health resources on capacity of Australian public sector nurses to deliver nursing care after-hours: a qualitative study. Nurs Inq. 2016;23:368-76.

68. Douglas CH, Douglas M. Patient-centred improvements in healthcare built environments perspectives and design indicators. Health Expect. 2005;8:264-76.

69. Daykin N, Byrne E, Soteriou T, O'Connor S. The impact of art, design and environment in mental healthcare: a systematic review of the literature. J R Soc Promot Health. 2008;128:85-94.

70. Martin D, Nettleton S, Buse C, Prior L, Twigg J. Architecture and health care: a place for sociology. Sociol Health Illn. 2015;37:1007-22.

71. Newman M, Thompson C, Roberts AP. Helping practitioners understand the contribution of qualitative research to evidence-based practice. Evid Based Nurs. 2006;9:4-7.

72. Swanson JM. Questions in use. In: Morse JM, Swanson JM, Kuzel AJ, editors. The nature of qualitative evidence. Thousand Oaks: Sage Publications; 2001. p. 75-110.

73. Pasche DR. National Humanization Policy as a bet to collective production of changes in management and care methods. Interface (Botucatu). 2009;13:701-8.

74. Silva RMCRA, Oliveira DC, Pereira ER, Silva MA, Trasmontano PS1, Alcantara VCG. Humanization of health consonant to the social representations of professionals and users: a literary study. Online Braz J Nurs. 2014;13:677-85. 